\title{
SOCIALIZAREA JUVENILĂ - TREAPTĂ PREMERGĂTOARE CEREMONIALULUI NUPȚIAL
}

\author{
Mariana COCIERU \\ Institutul de Filologie Română „B. P.-Hasdeu” al MEC
}

\begin{abstract}
Rezumat. In demersul de față autorul ia în discuție practicile de cultură tradițională cu valoare de socializare juvenilă a tinerilor care au atins vârsta maturitătiii. Actualizate în diverse contexte socio-culturale, obiceiurile de inițiere se inscriu în codul normativ al comunității, având rolul de a facilita trecerea tinerilor prin anumite protocoale sociale de integrare în rândul adulților. În majoritatea cazurilor, contextualizarea acestor obiceiuri avea loc in cadrul Horei (Jiocului, Jocului) satului, reprezentată ca o manifestare socio-culturală de anvergură în cadrul căreia își dădeau concursul instituția oamenilor în vârstă (ca sfătuitori și priveghetori asupra îndeplinirii cutumiare a rânduielii pământului) și instituția cetei de flăcăi (răspunzători de organizarea Horei satului și a obiceiurilor de inițiere intr-o clasă de vârstă). Literatura de specialitate, pune la dispoziția cercetătorilor fenomenelor etnoculturale mai multe informații referitor la intrarea tinerilor in ceata flăcăilor/feciorilor, în timp ce inițierea fetelor nubile rămâne din anumite considerente, neclare incă, un subiect mai puțin cercetat. Studiul de față reprezintă o investigație mai aprofundată a practicilor de modificare a statutului indivizilor ajunși in pragul maturității și o sintetizare a informațiilor obținute în vederea ințelegerii semnificațiilor celor două scenarii inițiatice pe sexe.
\end{abstract}

Cuvinte-cheie: fenomen etnocultural, obiceiuri de inițiere, socializare juvenilă, flăcău, fată mare, cultură tradițională.

Abstract. In this approach, the author discusses the traditional culture practices with the value of youthful socialization of young people who have reached adulthood. Updated in various socio-cultural contexts, the initiation habits are part of the normative code of the community, having the role of facilitating the passage of young people through certain social protocols of integration among adults. In most cases, the contextualization of these customs took place within the Village Hora I Hora satului (Joc or Jioc - The traditional Romanian circle dance), represented as a large socio-cultural event in which the institution of the elderly competed (as advisers and watchmen on the customary fulfillment of the land order) and the institution of the group of lads (responsible for the organization of the Village Hora and the habits of initiation into an age class). The literature provides researchers of ethno-cultural phenomena with more information on the entry of young people in the crowd of boys I girls, while the initiation of single girls remains for some reason, still unclear, a less researched topic. The present study represents a more in-depth investigation of 
the practices of changing the status of individuals who have reached the threshold of maturity and a synthesis of the information obtained in order to understand the meanings of the two initial scenarios by gender.

Keywords: ethno-cultural phenomenon, initiation habits, youthful socialization, lad, big girl, traditional culture.

Fiecare cercetare de teren, fie ea etnografică, folcloristică, sociologică, etnologică sau antropologică socio-culturală are menirea esențială de a demonstra complexitatea fenomenelor de cultură și civilizație tradițională, documentarea cărora deschizând perspective uimitoare de interpretare pentru știință, educație și cultura unui popor.

Caracterul perisabil al informației autentice ne motivează zilnic spre o documentare, tezaurizare și valorificare cât mai urgentă a faptelor etnoculturale pentru a preveni pierderea unor informații de valoare și perceperea în complexitate a elementelor de cultură și civilizație rurală.

Prin urmare, încercăm să aducem în discuție un subiect de interes socio-normativ, care la ora actuală se află într-o continuă degradare datorită revoluțiilor tehnologice care marchează considerabil comunitatea rurală, rupând-o involuntar de mentalitatea tradițională de odinioară și aruncând-o în vâltoarea tendințelor excesive de urbanizare și tehnologizare.

Cercetările actuale de teren ne prezintă informații diverse privind socializarea juvenilă, cele mai relevante pentru studiul dat fiind cele colectate din satele aflate la periferii, marginalizate și limitate în accesul excesiv către localitățile urbane. Informații utile au fost descoperite și în arhivele etnofolclorice și dialectologice, recent digitizate, care ne pun la dispoziție un model de existență pre-industrial, încă propice și relevant pentru investigațiile noastre.

În studiile de specialitate, riturile de trecere au cunoscut o reflectare considerabilă, fapt care demonstrează atât interesul sporit al cercetătorilor pentru aceste fenomene culturale, cât și pronunțatul caracter peren și multifuncțional al riturilor. Exegeții fenomenelor etnoculturale sunt de părerea că ritualurile vieții umane reprezintă zona cea mai productivă de cultură tradițională, iar cel mai bine conturat este cel nupțial, ca „verigă centrală și implicit, cea mai importantă a vieții” (Ciubotaru, 2009, p. 5). Argumentul acestei pertinente concluzii constă în faptul că ,spre deosebire de noul născut, care nu realizează implicarea lui în ritualurile pe care le parcurge ori de dalbul călător, aflat la cumpăna dintre existență și post-existență, cuplul marital își asumă lucid etapele ceremonialului, care îl va conduce la întemeierea căminului" (Ciubotaru, 2009, p. 5).

În aceeași ordine de idei, se înscriu și informațiile orale obținute în urma interviurilor realizate cu purtătorii de memorie culturală din localitățile 
din Republica Moldova, dar și cele românești din Ucraina și Federația Rusă, efectuate de colegii folcloriști în perioada postbelică, care ne aduc argumente suficiente în favoarea considerării ritualului nupțial drept cea mai spectaculoasă și complexă manifestare, de o valoare inestimabilă atât pentru cuplul familial format, cât și pentru întreaga comunitate rurală. Convins de acest fapt este Ioan Alexandru în prefața volumului Nunta la români. Orații, îngrijit de laboriosul cercetător al fenomenului nupțial Ion Moanță: „Nunta este socotită din vechime o taină ca și nașterea și moartea: spre deosebire de acestea însă, omul participă la nuntă conștient în ceasul de floare al viețuirii sale. Dacă nașterea corespunde zorilor viețuirii și moartea amurgului, nunta este ceasul de amiază, cel mai limpede pentru om, dar și cel mai greu tocmai datorită acestei limpezimi" (Alexandru, 1989, p. 5).

La hotarul dintre naștere și nuntă, se află perioada copilărie adolescență, definită de către etnologul Silvia Ciubotaru, drept „,vreme a așteptării și devenirii” care prin intermediul „sărbătorilor iniţiatice” realizează etapa premergătoare actului nupțial, de cunoaștere reciprocă a tinerilor și familiilor lor în cadrul mediului rural, la muncă - șezători, clacă, la sărbători calendaristice și de familie, la Hora satului, petreceri câmpenești, jocuri/baluri etc. (Moanță, 2014, p. 72).

În Registrul Național al Patrimoniului Cultural Imaterial, elaborat de Comisia Națională pentru Salvgardarea Patrimoniului Cultural Imaterial, obiceiurile de socializare a tinerilor sunt clasificate în felul următor: ieșirea la joc/horă, participarea la clacă, participarea în ceata flăcăilor, împreună cu toate practicile și reprezentările asociate acestora.

În grupul sărbătorilor comunitare cu funcție de inițiere sunt incluse: „V.61. Șezătoarea/La opaiț/La foc (la scărmănat sau la tors lâna, la țesut, la cusut cămășile și batistele pentru nuntă, la împletit haine de lână și horboțele pentru prosoape), împreună cu toate practicile și reprezentările asociate.

V.62. Claca la construit locuința (la pregătit lutul pentru casă, la făcut lampaci, la pus podul casei, la uns pereții) sau altă construcție din gospodărie.

V.63. Claca la construit biserica, împreună cu toate practicile și reprezentările asociate.

V.64. Întovărășirile de muncă la recoltat cerealele, la cules strugurii, la curățat porumbul și alte lucrări asemenea.

V.65. Hora/jocul satului, ca instituție de socializare a tineretului și de menținere a comunicării sociale, împreună cu toate practicile și reprezentările asociate (Zilele consacrate întrunirii horei/jocului. Intrarea tinerilor în horă. Invitarea fetelor la horă și petrecerea lor acasă. Grupul muzicanților. Angajarea/ tocmirea muzicanților și altele asemenea).

V.66. Spațiul de desfășurare a jocului/horei satului. 
V.67. Hramul bisericii și al localităţii, împreună cu toate practicile și reprezentările asociate (Serviciul divin, masa comunitară la biserică, hora/ jocul de după amiază. Jocul/hora de a doua și a treia zi de hram).

V.68. Spațiile consacrate pentru desfășurarea hramului” (Buzilă, 2012, cap. V).

Cadrul socio-normativ al acestor obiceiuri, practicate în cadrul sărbătorilor comunitare, era constituit din anumite legi nescrise, pe care membrii comunității le respectau în conformitate cu tradiția locală. De obicei, îndeplinirea acestor prevederi era reglementată de instituția oamenilor în vârstă, reprezentată de bătrânii satului și de grupul flăcăilor deja inițiați. Orice abatere de la conduita socială era supusă instanței tradiționale de judecată, de aceea membrii comunității se străduiau să nu le încalce și să le respecte întocmai.

Necesitatea trecerii acestor probe de socializare juvenilă, de inițiere, subliniază Adina Hulubaș, ,dă dreptul tinerilor să întemeieze o nouă lume mică, cea a familiei proprii - fiindcă au regenerat macrocosmosul prin victoria lor în probele mitice" (Hulubaș, 2007, p. 109). Inițierile copilăriei, când mama isși ghidează fiica în arta preparării bucatelor, a țesutului, a confecționării hainelor, îndeletniciri feminine necesare unei viitoare gospodine, iar tata își învață feciorul practicile agricole, cinegetice de dobândire a hranei, ca ocupații distincte masculine, însoțite de acele jocuri ale copilăriei în care sunt îndemnați a-și alege partenere, mimând inițiatic cererea în căsătorie sau dorința de nuntire, reprezintă etape de pregătire a copiilor pentru rolurile pe care și le vor asuma mai târziu, la vârsta pubertății. Inițial, într-un mod ludic, ulterior cu o mai multă responsabilitate, se realizează introducerea copiilor în viața socială a comunității. Participarea copiilor, alături de părinți, în activităţile sociale și etnoculturale ale mediului, urmărirea a ce se întâmplă cu frații sau surorile mai mari, ascultarea basmelor povestite de bunei cu FețiFrumoși și Ilene Cosânzene, deprinderea colindelor de flăcău și fată mare, de gazdă sau casă, executarea în formă de joc a unor practici magice rudimentare de aflare a ursitului etc., sunt tot atâtea experiențe de viață, obiceiuri, credințe care ,alcătuiesc un complex psihico-moral care înrădăcinează în conștiința fragedelor mlădiţe convingerea că, la vremea vremii, vor purcede pe calea întemeierii unei noi familii, că vor cunoaște dragostea și echilibrul sufletesc" (Ciubotaru, 2009, p. 40).

De aici preadolescenţii se îndreaptă spre etapa premergătoare actului marital - socializarea juvenilă, care în mentalitatea tradițională reprezintă o treaptă esențială pentru tinerii care urmau să se căsătorească. Băieții ajunși în pragul maturității trebuiau neapărat să iasă la horă, iar fetele mari să fie scoase la horă, în caz contrar, nefiind „lumiţi” (adică, dați cu lumea, socializați, inițiați), nu aveau permisiunea nici de ,a sta cu fetele sau cu băieții”, dar nici să se căsătorească. Era important ca această socializare să 
se producă și în urma inițierii fraților/surorilor mai mari. De asemenea, nu se permitea „să-i dai înainte” nici cu căsătoria, dacă, bunăoară în familie erau surori mai mari necăsătorite. Toate aceste legi nescrise erau respectate cu sfințenie. Rareori, încheierea căsătoriilor se efectua totuși cu acceptul fraților mai mari.

În continuare ne vom opri asupra rolului decisiv al Horei satului și al cetei de flăcăi/feciori în executarea actelor de socializare juvenilă.

Folcloristul Nicolae Băieșu în studiile sale consacrate sărbătorilor calendaristice, analizează Hora satului ca fenomen etnofolcloric important, aflat într-o interdependență inerentă de ceata de flăcăi, organizată în zilele de Crăciun, An Nou, Bobotează, Paște, Duminica mare, Hramul bisericii etc., în toate localitățile românești din Republica Moldova, Ucraina, Federația Rusă, întâlnită fiind și cu denumirea de Joc sau Jioc. Cercetătorul insistă asupra importantului rol educativ ce-l avea instituția tradiţională respectivă pentru întreaga comunitate: „Pe lângă elementul distractiv, jocul era un fel de școală a satului, o lecție de etică și estetică, dădea povețe de omenie, de comportare în societate, de popularizare a tot ce este frumos și de preț, totodată, de biciuire a obrăzniciei, a îngâmfării, fuduliei și altor metehne omenești” (Băieșu, 2014, p. 455). Tot aici evidențiază și starea actuală a fenomenului horal: „Regretăm mult că astăzi tradiția horei satului aproape nu mai există. Doar în foarte puține localități (or. Cahul, Brânzeni - Edineț și încă vreo câteva) se mai fac hore la sărbători, în același număr la Crăciun” (Băieșu, 2014, p. 456).

Un moment important pentru studiul iniţiat de noi este consemnarea de către folclorist a practicilor de inițiere a tinerilor efectuate în cadrul Horei de Crăciun, dar și la alte sărbători mari (Paștele, Duminica Mare, Hramul satului), identificate în cadrul campaniilor de teren cu denumirea: ,scosul la joc (n.n. - ieșitul la joc, ieșitul în lume) al fetelor (de 16-17 ani), dar și al flăcăilor începători. Scosul la joc, menționează cercetătorul, era trecerea solemnă a fetelor și băieților de la o categorie de vârstă la alta, care în trecut se efectua prin ceremonii speciale (deosebindu-se de la o zonă la alta) în fața întregii colectivităţi sătești. Era tranziţia de la vârsta copilăriei la cea a tinereții, când fetele și băieții pot de acum să se căsătorească, să formeze noi familii”" (Băieșu, 2014, p. 454).

Analizând manifestarea centrală din perioada sărbătorilor pascale, cercetătorul Victor Ghilaș e de părerea că „Hora satului contemporană prezintă o latură importantă a specificului spiritualităţii naționale românești, conturându-i identitatea în lumea pluralistă și globalizantă. În același timp, ea consfințește rezultatul tezaurizării unor valori fundamental-umane în tradiția populară, ca formă vie de manifestare socioculturală a comunității ce respectă și construiește bunuri cultural-artistice colective" (Ghilaș, 2008, p. 19).

Cele două instituții tradiționale, Hora satului și Ceata flăcăilor, care au stat la baza consolidării culturii socio-normative tradiționale, sunt tratate 
minuțios și în studiile etnologului Varvara Buzilă: „Până la apariția legilor scrise, dar în bună parte și după aprobarea pravilei, instituțiile sociale, constituite și esențializate în așa mod încât să articuleze întreaga cultură tradițională, vegheau asupra respectării normelor sociale, fiind orientate de sistemul de valori specific acestei societăți. Principiile valorice ale acestui drept obișnuielnic, fidel tradiţiei, erau promovate conform unor modele consacrate, considerate de către mentalitatea tradiţională ca fiind foarte vechi și cele mai adevărate" (Buzilă, 2014, p. 107).

Atât documentele de arhivă manuscriptice și sonore ale Arhivei de Folclor a Institutului de Filologie Română „Bogdan Petriceicu-Hasdeu”, cât și studiile privind rezultatele unor cercetări de teren în satele dintre Prut și Nistru, dar și propriile experiențe de culegător și cercetător al fenomenului etnocultural Hora satului și al obiceiurilor aferente, ne-au demonstrat că informatorii/performerii de folclor dețin în memoria colectivă cunoștințe cu privire la aceste practici de inițiere. Nivelul de conservare a informațiilor privind aceste practici în memoria promotorilor de folclor e unul diferit. Etnologul Varvara Buzilă concluzionează că cel mai frecvent, purtătorii de cultură tradițională ,povestesc despre intrarea flăcăilor în horă și mai puțin despre iniţierea fetelor” (Buzilă, 2014, p. 107). Cu toate acestea, în timpul cercetărilor am identificat informații suficiente și diferite privind socializarea de gen.

Chiar dacă în Europa întreagă, constată filosoful religiilor Mircea Eliade, au dispărut inițierile tradiționale ale lumii arhaice, în mediul cultural românesc acestea s-au conservat prin simboluri și scenarii consolidate în vise și în imaginația subconștientă a mentalului folcloric (Eliade, 1994, p. 177). Etnologul Adina Hulubaș cercetează manifestarea tiparelor iniţiatice în folclorul literar care păstrează aspectul metaforizat al acestor ritualuri. Analizând literatura de specialitate, exegeta constată o lipsă desăvârșită a studiilor destinate modelelor iniţiatice, considerând contribuţia lui Eliade la investigarea și interpretarea religiilor lumii una fundamentală în descifrarea simbolismului inițiatic concentrat în ritualuri și considerate drept forme/fapte de manifestare culturală străveche.

Din perspectivă teoretică, conceptul de iniţiere este definit în literatura de specialitate din perspectiva a trei ritualuri:

$>$ iniţierea tribală - trecerea de la statutul de adolescent la cel de tânăr cu drepturi depline în societate; rituri de pubertate sau iniţiere de la o clasă de vârstă la alta, sau rituri de socializare juvenilă;

$>$ iniţierea religioasă;

$>$ iniţierea într-o societate secretă.

În prezentul demers ne vom referi doar la inițierea tribală, pe care am putea să o numim și inițierea de obște, comunitară, socială. De la bun început, antropologul francez Arnold van Jennep ne atenţionează să nu confundăm 
ritualurile de pubertate socială cu cele de pubertate fizică sau sexuală, care nu coincideau în majoritatea cazurilor, considerând inițierea ca pe niște ,rituri de separare de lumea asexuată, urmate de rituri de agregare la lumea sexuală, la societatea restrânsă, constituită dincolo de toate celelalte societăți generale sau speciale, din indivizi de același sex" (Gennep, 1996, p. 69).

Insistând asupra simbolisticii ritualurilor de trecere, vom constata că Mircea Eliade identifică în fiecare trecere de prag un moment critic de moarte ritualică, „supremă inițiere” (Eliade, 1993, p. 242, p. 244), care marchează începutul unei noi existențe spirituale: „inițierea echivalează cu maturizarea spirituală" (Eliade, 1995, p. 164). Pragurile respective determină și depăşirea sinelui individual și unirea cu ființa absolută. Prin urmarea, intratul în horă și prinderea în joc pot fi interpretate pe de o parte ca pe „,refacerea întregului, pentru că în timpul sărbătorilor omul simte cel mai puternic legătura sa cu Totul”, pe de altă parte, are loc „restabilirea legăturilor cu sacrul”, deoarece ,accesul la sacru permite contactul cu Totul, împreună conducând la anularea necunoscutului în cunoscut; iar Cosmosul devine transparent" (Suiogan, 2006, p. 39).

Toate aceste tipare erau o reiterare a acțiunilor arhetipale transmise din generație în generaţie la nivel genetic. Acțiunile intenționate erau orientate spre depășirea stării anterioare și atingerea stării superioare. Comportamentul celui iniţiat se realiza în rezultatul osmozei aspectelor particulare cu cele generale. Rolurile actanților la respectivul model sociocultural, subliniază Germina Comanici, ,se creează pe un sistem de valori, cu un model concret de realizare, într-un raport de determinare între interpretul - posibil și creator - și colectivitatea prezentă, care receptează, dar și cea precedentă, care a contribuit la realizarea modelului. Astfel, schema de rol, ca element al paternului cultural, este o rezultantă de generații” (Comanici, 1992, p. 55).

Riturile de inițiere legate de atingerea maturității cuprind, după Mircea Eliade, o serie de elemente comune. Vom încerca să exemplificăm aceste componente prin raportarea la informațiile înregistrate pe teren cu referire la aceste practici de inițiere:

- separarea de mediul familiar (prin actele de înfrățire sau luarea de surate, intrarea flăcăilor în ceata bărbătească, a fetelor mari în hurtă), izolarea (așa cum o făceau băieții în hurdughii, iar fetele la șezători);

- interdicțiile (fata mare nu trebuia să fie văzută de acei ai casei când trebuia să se gătească pentru horă, pentru a nu-i fi furat meșteșugul rumenelii);

- schimbarea aspectului prin vopsire, măști, deghizări (la horă atât tânărul, dar mai ales fata mare trebuia să iasă rumenită, în straie noi, cu anumite obiecte ritualice, așa cum era batista, băsmăluța de horă, busuiocul pus în sân, atât cu semnificație apotropaică, cât și ca element magic de ademenire a partenerilor de sex opus, busuiocul - dragostea feciorilor); 
- supunerea în fața unui „lider" (și aici ne referim la existența unui flăcău cu rol central în ceata feciorilor, numit cămăraș sau calfă, vătaf, iar daca ne referim la fete, fiecare fată mare avea o prietenă deja inițiată, care o îndruma în tainele feminității);

- transmiterea unor cunoștințe considerate secrete (acestea se referă la comportamentul flăcăilor față de fetele mari, și viceversa);

- trecerea testelor și probelor pentru cei care erau inițiați (mânuirea căilor de către flăcăi, capacitatea de a face plăți atât pentru horă, cât și intrarea în horă, mânuirea abilă a repertoriului coregrafic, pentru fetele mari proba consta în pregătirea colacului pentru colindători, dar și a zestrei pentru viitoarea căsătorie, pregătirea băsmăluței pentru horă, a straielor pentru ieșirea în lume etc.) ș.a.

În continuare, vom încerca să descifrăm mai detaliat semnificația și rostul obiceiurilor de socializare a tinerii generații.

Etnologul Ovidiu Bârlea subliniază în renumitul său Eseu despre dansul popular românesc, că, în comparație cu alte categorii ale artei tradiționale, anume dansul avea un rol social foarte important, deoarece dansul „era practicat de toți cei valizi, mișcarea ritmică fiind la îndemâna oricui fără să necesite auz muzical, har poetic sau simț plastic", elementul coregrafic era „un coagulant puternic al obștilor țărănești din toate timpurile, a transformat adunătura satului într-o singură ființă a cărei inimă e în stare să pulseze simultan pe ritmul jocului" (Bârlea, 1982, p. 20). Din aceste considerente și obiceiurile de socializare ale tinerilor se performau, cu predilecție, în cadrul manifestărilor sociale însoțite de elementul coregrafic sau nemijlocit în cadrul acelor manifestări unde dansul deținea întâietatea. Deoarece, dansul, „oferă cele mai propice posibilități de dezvăluire a individualităţii umane”, el devine „limbajul cel mai comod pentru exteriorizarea personalității” (Bârlea, 1982, p. 21) și care, de altfel, poartă „pecetea” tuturor, a colectivității. Potrivit etnologului Bârlea, deși cultivarea individului prin „euforie coregrafică” vine în contradicție cu ,aserțiunea despre virtutea dansului de a integra individul în grup, de a cimenta coeziunea socială a comunității rurale", în cele din urmă, aceste două aspecte se întrepătrund, se completează, formând un echilibru: „unele dansuri deservesc mai mult integrarea în comunitate, cu tendința de subordonare a individualităţii, pe când altele favorizează expansiunea eului, promovând o adevărată dilatare a personalității jucătorului” (Bârlea, 1982, p. 24).

Dansurile cu substrat cultic, aveau menirea de a marca o trecere, prin urmare și dansul din cadrul Colindatului de Crăciun în unele zone etnografice ,a mai păstrat până în vremea din urmă câteva din prerogativele de inițiere în joc" (Bârlea, 1982, p. 31). Astfel, intrarea tinerilor în joc marca momentul maturitătii și se făcea printr-un anumit protocol social, anume în pereche, dovedind capacitatea de integrare în comunitatea maturilor, cu perspectiva căsătoriei. Potrivit tradiției fata mare trebuia introdusă în horă, adică iniţiată, doar în cadrul horei satului organizată la sfârșirea Colindatului ritualic de Crăciun: „,se denumea unul din ceată, vătaful mic (care era și ajutor al vătafului), 
sau cu nume și mai sugestiv, trăgătoriu de fete, care avea obligația de a lua la joc fetele pubere încă neparticipante la horă. În conformitate cu datina, fata se opunea formal, de aici nevoia unui efort din partea celui însărcinat ce se întrevede și din numele ce i s-a dat. Acest prim joc era un dans de inițiere, prin care fata era de aici înainte integrată în rândul celor «mari», aptă de a răspunde noilor solicitări sociale" (Bârlea, 1982, p. 31).

Vârsta ieșirii nubililor la horă sau în lume varia de la 14-15 ani până la 19-20. În satele din valea Prutului de Jos, deoarece era permisă participarea copiilor și a minorilor la horă, momentul socializării juvenile avea loc mai devreme și decurgea într-un mod firesc, căsătoriile înfăptuindu-se pe la 16 ani. În satele cu o cultură arhaică pronunțată, conservativă, socializarea avea loc mai târziu - 18-20 ani, întrucât copiii erau ținuți mai departe de horă, nu li se permitea să participe, deoarece nu aveau anii, iar hora era considerată drept manifestare de cunoaștere a tinerilor pentru încheierea căsătoriilor ulterioare și nu o petrecere distractivă. În aceste localități și implicarea celor căsătoriți era limitată, având dreptul de participare doar proaspetele familii, vârstnicii deținând cu totul alte obligații în cadrul acestor socializări.

Iniţierea juvenilă se producea mai ales dacă se respectau și alte condiții, adică dacă tinerii erau pregătiți de a manevra practicile și ocupațiile tradiționale de gospodărie. Flăcăul trebuia să știe/ să cunoască muncile câmpului, să poată călări și să fie capabil să-și ridice o casă, să știe a juca/dansa repertoriul coregrafic al localității de origine, să cunoască și să fie fiziologic pregătit de a întemeia o familie, să poată plăti taxa de inițiere etc., fata trebuia să știe a toarce, a țese, a coace, a face mâncare, a ține/îngriji de casă, să aibă zestrea gata, neapărat trebuia să-și croșeteze și brodeze băsmăluța de horă pe care urma să o dăruiască în semn de fidelitate viitorului iubit, să-și confecționeze straie noi, să se fardeze, să primească flăcăii cu colac la colindat/urat, să fie achitată taxa de către părinți, să fie obiectul-subiect al colindatului. Numai dacă corespundeau acestor cerințe aveau dreptul de a ieși la horă, de a-și alege prieteni și de a încheia căsătorii.

Mai mult decât atât, fără a fi inițiat in cadrul horei, nu puteai fi acceptat în ceata flăcăilor colindători, hora fiind considerată o etapa de socializare cu lumea satului, numită ieșirea în lume, și care îți permitea să participi la actul ritualic al colindatului, acesta fiind mult mai superior ca semnificație cutumiară decât celelalte acte, cum ar fi bunăoară participarea flăcăilor inițiați la ,șezătoare”, „,opaiț”, „, la scosu-n tindă” sau „,de-a lungul drumului/la brațetă”.

Cât privește inițierea fetelor in cadrul horei satului, trebuia să se înfăptuiască în urma actului ritualic de a fi colindată, deoarece colindele prin cuvintele lor încărcate magic înfăptuiau reinstaurarea lumii mitice, unde personajele principale se metamorfozau în strămoșii întemeietori ai lumii: alături de Dumnezeu, sfinți, primii oameni: Adam și Eva: „Personajul evenimentelor mitice este chiar tânărul/tânăra de la casa colindată, numele lui/ei apare în textul ceremonial și îl investește cu toată energia numinoasă 
de care va avea nevoie în anul următor pentru a se împlini social" (Hulubaș, 2009, p. 598).

Ieșitul în lume a fetelor mari era mai puțin spectaculos decât al flăcăilor, concluzionează Varvara Buzilă. Cu toate acestea, exegeta ne comunică câteva momente specifice unor sate din Basarabia: ,în unele localități, dacă fata a fost jucată pentru prima oară de către flăcăi în curtea casei părintești în timpul colindatului, sau a fost invitată cu muzică de acasă înainte de începutul horei, aceste gesturi aveau valoare de intrare în horă. Dar era acceptat și gestul ca un flăcău care dorea să joace cu o fată nejucată încă să ceară ajutorul altora, mai inițiați, și aceștia i-o aduceau, prinzând-o alături de el în horă. Din acel moment se considera că ea este intrată în horă" (Buzilă, 2014, p. 119).

În continuare vom aduce câteva informații cu referire la obiceiurile de socializare juvenilă depistate în materialele etnofolclorice prezervate în Arhiva de Folclor a Institutului de Filologie Română „Bogdan Petriceicu-Hasdeu”. Socializarea flăcăilor și a fetelor mari: „Băietu când ișă la jioc pune mohorâci la șeilalț flăcăi, mai mari. Tat-su îl scote la jioc, la șăptispreși ani. Părințî trebu' s-punî mohorâci. Pune vadra. Ori fata. Iaca, dacî i-o scos fata la jioc, părințî pune mohorâci. O vadrî di jin - c-o scos fata la jioc" (AFIFRBPH, 1988, ms. 390, f. 230); „Vine băietu acasă la fată, s-o scoată la jioc. Fata al chiamă în casă, îi dă v-on păhar di jin, al pune la masă și al hrănește. Pe urmă să pornesc la jioc. Fata ie în basmaluță niște preanișe e* și un șip de jin. Să duc la jioc. De departe le dău Marș” (AFIFRBPH, 1946, ms. 5, f. 119); „Flăcău vine la fata cu cari prietene ș-o dușe la jioc. E sî găte cu dulcețuri. Li pune într-un tulpan**. $<\ldots>$ Dimineața (fata) pune la muzâcanț pi masî < ..> meri, nuși. Sî număra cî e-i di gospodari, fatî di frunti" (AFIFRBPH, 1987, ms. 383, f. 158).

$\mathrm{Au}$ fost consemnate în cadrul cercetărilor de teren situații când scoaterea/ieșitul fetelor la joc de Crăciun revenea, din punct de vedere al socializării normative, cetei flăcăilor colindători. De obicei invitarea fetei la horă avea loc, după ce dânsa înmâna colacul special pregătit colăcarului sau vătavului cetei de colindători/urători (părințiii fetei aveau grijă ca ceata să fie răsplătită și cu surse financiare, necesare „,arvonirii/tocmirii/năimirii” muzicanților pentru Hora satului).

În timpul horei tradiționale avea loc (în cazuri destul de rar întâlnite, denigratoare pentru imaginea unei fete) - scosul demonstrativ al fetelor din joc pentru o anumită perioadă: ,Dacă o fată nu are plăcerea să danseze cu un flăcău, care, poate, e mai sărac sau nu se bucură de o bună reputație în sat, atunci flăcăul o poate da afară din joc. Îi spune «Du-te la tat-to și la mă-ta să-ți facă joc» (Inform. Mașa Curagău, 25 de ani, Iurceni). Fata stă între fete și nu dansează, chiar dacă o cheamă alți flăcăi, care-i sunt pe plac. Flăcăul jignit o poate împiedica să danseze, izbind-o afară din joc. Alți flăcăi îi pun pe lăutari să-i cânte marșul (s. n.)" (pentru fata scoasă din joc) (Iurceni Nisporeni; Ștefănucă, 1991, p. 124); „Dacî eu vrem sî jioc cu dânsa, da e nu

* Prianic (rus.) - turtă, turtiţă.

** Tulpan - basma, batic. 
vra, apu' spunem la așeal mai mari pi jioc, la cămărașu: - Eu pi asta am s-o dau afarî din jioc!/ - Da di și? / - Nu vra sî jioși cu mini!/ < ..> Mă dușem ș-o luam di speti șîi-i dam un jenunchi în cur șî: - Ieș din jioc!/ O rușînam, dacî nu vra si jioași cu mini. O scotem./ Culeg.: Ce făcea fata pe urmă?/ Inf.: Șîde dioparti. Niș acasî nu sî dușe. Șîde șî tătî vremea plânje. Șî fetili: - Ia, lasî, cî, el, o sî-i treacî șî mâni ai sî jioși./ Apu' (a doua zi) vine șî: - Măi, las-o, săraca. Nu, e s-o oșâbit ${ }^{* * *}$, poati. Da astâz, dacî-i chema-o, a sî jioași o zâs - cu tini./ Ș-apăi mă dușem șîi-i spunem: - Ai sî vii sî jioși?/ - Ám sî vin!/ - Da disarî sî vin la tini?/ - Vinî!" (AFIFRBPH, 1988, ms. 388, f. 99-100); „Dacă băieții au șiudă pe v-o fată, apoi la joc când o duc, o joacă v-on joc ș-apoi îi dău Marș, adică o dă afară din joc. Pe așa fată o râd băieții” (AFIFRBPH, 1946, ms. 5, f. 119); „Pi fata șeea pi cari ave hreap ${ }^{* * * *}$ o scote din jioc. Iaca, eu nu vrem sî grăiesc cu dânsu. El trebuie sî-ni cânti Marș. Mă scote din jioc" (AFIFRBPH, 1988, ms. 390, f. 231).

Concluzionând asupra celor expuse, vom sublinia că obiceiurile de inițiere, actualizate în practică, reprezintă niște jocuri ritualice care realizează ceremonialul de trecere (separare de lumea copilăriei și integrare în comunitatea flăcăilor/fetelor mari ,bune de măritat”), având la bază niște tipare arhaice moștenite de veacuri. Fiecare individ inițiat repeta în mod cutumiar prevederi socio-normative deja consolidate, trecute prin tradiție, devenite rânduieli cu valoare sacră. Grupul care îl ajuta în traseul inițiatic urmărea ca aceste reguli să fie îndeplinite întocmai pentru ca în acest scenariu ritualic de inițiere să se realizeze recondiționarea vechiului individ într-o personalitate nouă. Prin urmare, inițierea în contextul Horei satului repetă tiparele arhaice de inițiere efectuate odinioară în cadrul ritualurilor mimetice preistorice, iar dansul, încărcat simbolic de gesturile arhetipale ale vechilor lupte cu forțele divine, facilitează trecerea celui care se inițiază din lumea profană în cea sacră.

\section{Referințe bibliografice:}

1. AFIFRBPH, 1946, ms. 5, f. 119; Mahala - Dubăsari; inf. T. D. Basiul, 40 ani; culeg. M. Barcari.

2. AFIFRBPH, 1946, ms. 5, f. 119; Mahala - Dubăsari; inf. T. D. Basiul, 40 ani; culeg. M. Barcari.

3. AFIFRBPH, 1987, ms. 383, f. 158; Speia-Grigoriopol; inf. Ştefan M. Eftodiev, 65 ani; culeg. N. Băieșu.

4. AFIFRBPH, 1988, ms. 388, f. 99-100; Moldovanscoe - Crâmsc - Crasnodar; inf. Toader G. Midonii, 76 ani; culeg. E. Junghietu.

5. AFIFRBPH, 1988, ms. 390, f. 230; Nezavertailovca - Slobozia; inf. Maria L. Stepanov, 55 ani; culeg. E. Junghietu.

6. AFIFRBPH, 1988, ms. 390, f. 231; Nezavertailovca - Slobozia; inf. Maria L. Stepanov, 55 ani; culeg. E. Junghietu.

7. ALEXANDRU, Ioan. Semnificația nunții. În: MOANȚ Ă, Ion. Nunta la români. Orații. Ediție îngrijită de Ion Moanță. București: Minerva, 1989, p. 5-14.

*** Oşibitisea (rus.) - a greşi.

**** Hleap, hreap - ciudă. 
8. BĂIEȘU, Nicolae. Obiceiurile și folclorul sărbătorilor de iarnă (Tipologie. Corpus de texte etnografice și folclorice). Partea I. Chișinău: Tipografia Centrală, 2014.

9. BÂRLEA, Ovidiu. Eseu despre dansul popular romanesc. București: Cartea Românească, 1982.

10. BUZILĂ, Varvara. Ceata flăcăilor și Hora satului - instituții tradiționale de afirmare a culturii socio-normative. În: Buletin Științific. Revistă de Etnografie, Științele Naturii și Muzeologie. 2014, Volumul 21 (34), p. 107-124.

11. BUZILĂ, Varvara. V. Sărbătorile, obiceiurile și ritualurile. În: Registrul Național al Patrimoniului Cultural Imaterial. Chișinău: Lumina, 2012. (online) Disponibil: http://www.patrimoniuimaterial.md/ro/pagini/registrul-conținutul-registrului-naționalal-patrimoniului-cultural-imaterial/capitolul-v (citat 21.09.2021)

12. CIUBOTARU, Silvia. Obiceiuri nupțiale din Moldova: tipologie și corpus de texte. Iași: Editura Universității „Al. I. Cuza”, 2009.

13. COMANICI, Germina. Sincretismul limbajelor în modelul de rol al obiceiurilor populare. În: Anuarul Institutului de Etnografie și folclor „C. Brăiloiu”. Serie nouă. București: Editura Academiei Române, 1992, tom 3, p. 55-69.

14. ELIADE, Mircea. Arta de a muri. Iași: Moldova, 1993.

15. ELIADE, Mircea. Nostalgia originilor. Istorie şi semnificație în religie. Traducere de Cezar Baltag. București: Humanitas, 1994.

16. ELIADE, Mircea. Sacrul și profanul. Traducere de Brânduşa Prelipceanu. București: Humanitas, 1995.

17. GENNEP, Arnold Van. Riturile de trecere. Traducere de Lucia Berdan și Nora Vasilescu. Studiu introductiv de Nicolae Constantinescu. Postfaţă de Lucia Berdan, Iași: Polirom, 1996.

18. GHILAȘ, Victor. Hora satului de Paște-marcă purtătoare de cultură și tradiție națională În: Patrimoniul cultural: cercetare, valorificare, promovare, conferință (12; 2020; Chișinău). Materialele conferinței «Patrimoniul cultural: cercetare, valorificare, promovare», Ediția a 12-a, Chişinău, 28-29 mai 2020. Coordonatori: Victor Ghilaș, Adrian Dolghi; colegiul redacțional: Victor Ghilaș (președinte) [et al.]. Vol. I. Chișinău: Institutul Patrimoniului Cultural, 2020, p. 15-21.

19. HULUBAȘ, Adina. Implicații mitice ale inițierii feminine. În: Anuarul Muzeului Etnografic al Moldovei. 2007, nr. 7, p. 109-136.

20. HULUBAȘ, Adina. Inițierea. Definiții europene și tipare românești. În: Distorsionări în comunicarea lingvistică, literară şi etnofolclorică românească şi contextul european. Iași: ALFA, 2009, p. 597-613.

21. MOANȚĂ, Ion. Nunta românească și cântecele ei. Prezentare tematicomotivică (I). În: Ghidul iubitorilor de folclor. Suceava: Lidana, 2014, nr. 4, p. 69-114.

22. SUIOGAN, Delia. Simbolica ritualurilor de trecere. București: Paideia, 2006.

23. ȘTEFĂNUCĂ, Petre V. Folclor și tradiții populare. Alcătuire, studiu introductiv, bibliografie, comentarii și note de Grigore Botezatu și Andrei Hîncu. Vol. II. Chișinău: Știința, 1991.

Notă: Articolul a fost realizat în cadrul proiectului de cercetare 20.80009.1606.03 Contexte socioculturale autohtone şi interconexiuni europene în creaţia populară şi literatura cultă din Basarabia (sec. XIX până în prezent), Institutul de Filologie Română „B. P.-Hasdeu” al MEC. 